\title{
Sanayi İşletmelerinde Çevre Bilinci ve Yeşil Yönetim Üzerine Bir Değerlendirme
}

\author{
DOI: 10.26466/opus.779229
}

*

\section{Ergün Kara* - Attila Kaya **}

* Doç. Dr. Osmaniye Korkut Ata Üniversitesi, İ.̇̇.B.F, Osmaniye/Türkiye E-Posta: ergunkara@osmaniye.edu.tr

ORCID: 0000-0002-7815-1111

** Dr. Öğrencisi, Osmaniye Korkut Ata Üniversitesi, Sosyal Bilimler Enstitüsü, Osmaniye/Türkiye E-Posta: akaya501616@gmail.com

ORCID: 0000-0002-2479-5173

\section{Öz}

Tarihi çağlardan beridir insanların ihtiyaçların karşılanması için üretim faaliyetleri aralıksız olarak devam etmektedir. Sanayi devrimi sonrasında makineleşmenin bir sonucu olarak artan hammadde ihtiyacının karşılanmasında doğal kaynakların hoyratça ve özensiz kullanılması çevre üzerinde giderek artan bir tahribata yol açmıştır. Özellikle sanayi işletmelerinin ortaya çıkardığı bu olumsuz durumun engellenmesi adına tüm dünyada çeşitli adımlar atılırken, organizasyonlar da sürdürülebilir üretim arayışları kapsamında yeşil yönetim anlayışını benimsemeye başlamışlardır. Yeşil yönetim anlayışı ile işletmeler, üretim faaliyetlerinde çeorenin korunmasına azami özen gösterirlerken onun korunması adına da yeni projeler geliştirerek gelecek kuşaklara sağhlklı bir doğa bırakmanın amacı gütmektedirler. Kısacası geleceğimiz açısından sürdürülebilirliğin işletmeler açısından artık zorunlu bir sorumluluk olduğundan bahsedilebilir. Yerli yazında yeterli çalışma olmadığından dolayı çevre bilinci ve yeşil yönetim konularına ă̆ırlık verilmiştir. Bu çalışmada sanayi işletmelerinin çevre üzerindeki olumsuz etkilerinin en az seviyeye indirilmesi için uygulanan yeşil yönetim felsefesinin işletmeler üzerindeki etkileri ilgili literatür ışı̆̆ında incelenmiş ve ne şekilde gerçekleştirilebileceği üzerine genel bir değerlendirme yapılmiştır.

Anahtar Kelimeler: Sanayi İşletmeleri, Çevreci Üretim, Yeşil Yönetim, Çevre Bilinci 


\title{
Environment Consciousness in the Industrial Businesses and an Evaluation on Green Management
}

\begin{abstract}
Production activities have constantly been continuing to cover people's needs since historical ages. The extravagant and careless usage of natural sources in meeting the need of raw material as a result of mechanisation after industrial revolution has caused an increasing destroy on the environment. Various steps are taken in all the world on behalf of preventing this negative situation especially created by industrial managements, organisations have started to adopt the green management understanding within the scope of sustainable production insight. While managements show the uttermost care to protect the environment in the production activities by green management understanding, they also aim at leaving a heal thy nature for future generations by developing new projects to protect the nature. To sum up, an obligatory responsibility can be talked about for managements in terms of sustainability for the sake of our future. Since there is not enough work in the local literature, environmental awareness and green management issues have been emphasized. The effect of the applied green management philosophy on managements to be able to minimize the industry managements' negative influences on the environment has been studied in the light of related literature and an overall evaluation has been done.
\end{abstract}

Keywords: Industrial Enterprises, Environmentally Friendly Production, Green Management, Environment Awareness 


\section{Giriş}

Çevre ve insan ilişkisi, yaşamın bir zorunluluğu olarak sonsuza kadar sürecek karmaşık ve yıpratıcı bir bütünü oluşturmaktadır. Bu nedenle insanın çevreden bağımsız olması düşünülemez. Ancak bu ilişkide insanlar çevreyi koruma konusunda yeteri kadar özenli davranmadıkları için günümüzde gelinen nokta doğal çevrenin tahribatı konunda facia noktasına ulaşmıştır. Yakın sayılabilecek bir tarihte insanlık için büyük bir dönem noktası olan makinenin icadı her alanda işleri hızlıca kolaylaştırırken, doğal çevremizi de bir o kadar kısa sürede tahrip edeceğini şüphesiz kimse düşünmemişti. Üretimdeki artışa paralel olarak birçok sektör gelişmiş küresel boyutta fabrikalar kurulmuş, teknolojik olarak geliştirilen makine ve teçhizatlar ile üretim kapasitesi daha da artırılmıştır. Ancak bu yoğun üretim, doğal kaynakların hızlı tüketilmesi, hava, su, toprak ve gürültü kirliliği ile ekolojik dengenin bozulması gibi sıkıntıları beraberinde getirmiştir (Haden vd, 2009).

Günümüzde gelinen noktada ise insanların çevre konusunda daha bilinçli olması, tüm dünyada uygulamaya konulan yasal düzenlemeler ve sosyal örgütlenmeler, işletmeleri bu konuda kendilerini topluma karşı sorumlu hissetmeleri açısından önemli bir baskı oluşturmuştur. Artık 21. yy'da işletmeciliğin temel konularından birisi de çevreye duyarlı üretimin ne şekilde yapılacağı oluşturmaktadır. İşletme misyonunda etkili bir çevre yönetimi için öncelikle yönetimsel olarak bir değişim gerekmektedir. Bu nedenle işletme faaliyetleri ile planlarını doğal çevreye duyarlı olacak şekilde tasarlayacak ve yürütecek yeşil yönetim anlayışı ortaya çımıştır (Akdoğan, 2003).

Üretimsel ve çevresel sürdürülebilirliğin sağlıklı bir şekilde yürütülebilmesi amacıyla uygulanan yeşil yönetim anlayışında doğal çevrenin korunması esastır. Üretimden pazarlamaya, finansmandan dağıtıma, insan kaynaklarından müşteri ilişkilerine varıncaya kadar işletmenin her alandaki faaliyetinin çevre bilinci doğrultusunda tasarlanması yeşil yönetim sayesinde olacaktır. Aslında bu yönetim anlayışının isminden dolayı sadece çevrenin korunması için geliştirilmiş bir yönetim modeli olduğu düşünülmemeli. Yeşil yönetimin temel hedeflerinden birisi de işletmenin rekabet gücünü artırmak, müşterileri ve topluma karşı sempatiklik kazanmak, bu şekilde misyon ve vizyon hedeflerine ulaşmaktır. Bu doğrultuda çalışmada, çevrenin korunması açısından son derece önemli olan yeşil yönetim uygulamalarının sanayi 
işletmelerine olan faydaları literatür ışığında incelenmiş, genel bir değerlendirme yapılmıştır ve yeşil yönetimin daha sağlıklı bir şekilde yürütülebilmesi için öneriler geliştirilmiştir.

\section{Sanayi İşletmeleri ve Çevre İlişkisi}

Üretim yapısal olarak doğal kaynaklara bağımlı olduğu için yakın bir ilişki içerisindedirler. Çağımızda insanların beklenti ve istekleri değiştikçe, çeşitlenen üretim faaliyetleri için gerekli olan kaynakların temin edilmesinde sıkıntılar yaşanmaktadır. Zaten kıt olan doğal kaynakların gelişigüzel ve plansız harcanmasının gelecek dönemlerde bir felakete sebep olacağından, işletmeler artık verimlilik ve karlılık yanında ekolojik dengenin korunmasına yönelik tedbirleri hedefleri arasın alarak faaliyette bulunmaktadırlar. Bu fikir doğrultusunda oluşturulan "Çevreye duyarlı işletmecilik" kavramının en önemli aktörleri sanayi işletmeleridir. Üretim konusunun ana unsurları olan sanayi işletmeleri faaliyet konularına göre doğanın temel elementleri üzerinde tamiri imkansız zararlar verebileceğinden, çevrenin korunmasına yönelik en önemli tedbirlerinde bu işletmeler tarafından alınması gerekmektedir. Sağlıklı ve başarılı bir çevre yönetimi için işletme organlarının misyon hedeflerin uygun olarak bir bütün olarak hareket etmesi, faaliyetleri şekillendiren tüm etkenlerin (paydaşlar, müşteriler, ortaklar, yasal zorunluluklar) istek ve beklentilerini dikkate alan bir yapı içerisinde hareket etmesi gerekir(http://ekolojist.net).

Sanayileşme yolunda olan ülkelerde diğer ülkelere oranla daha fazla doğal çevre tahribatı görülmektedir. Gelişmiş ülkelerde çevrenin korunması konusunda gerekeli tedbirlerin alınması ve uygulanmasında belirli bir standart yakalanmışken, az gelişmiş veya gelişmemiş ülkelerde sanayi üretimi zayıf olduğu için çevre tahribatı ve korunması konusunda henüz önemli bir fikir oluşmamıştır. Bu nedenle gelişmekte olan ülkelerde yoğun bir sanayi hamlesinin bulunması ve çevre bilincinin yeterince oluşmaması bu konudaki en önemli tehlike olarak görülebilir. Maden sahaları ve taş ocakları gibi alanlarda gelişigüzel yürütülen hammadde arayışları, geri dönüşümsüz üretim faaliyetleri, enerjini kontrolsüz kullanılması, katı sıvı ve gaz atıkların filtrelenmeden doğaya bırakılmasının etkileri günümüzde açıkça görülmektedir. Diğer taraftan üretim süreci sonucunda ortaya çıkan tehlikeli gazlar yüzünden sadece o bölgeler değil dünyanın tamamı tehlike altına girmektedir. Sera 
gazı etkisi sonucunda oluşan asit yağmurlarının Kuzey Avrupa ülkelerini tehdit etmesi bunun en güzel örneğidir. Radyo aktif enerji kullanarak üretim yapan tesislerin sorunları ise çevre kirliliği yanında Çernobil'de yaşanan facia gibi insan hayatı üzerinde doğrudan ölümlere sebep olabilecek ürkütücü sonuçları da olmaktadır. Ayrıca sanayi işletmelerinin tüm bu olumsuz sonuçlarının ortaya çıkardığı en önemli genel problem ise küresel iklim değişikliği sorunudur (http://ekolojist.net).

Tüm dünyada çevre konusunda ortaya çkan bu olumsuz tablo nedeniyle uluslararası alanda artık önemli kararlar alınmaktadır. 1972 yılında Stockholm Konferansında 5 Haziran tarihinin "Dünya Çevre Günü" ilan edilmesi, 194 ülke tarafından imzalana ve 1994'te yürürlüğe giren Birleşmiş Milletler İklim Değişikliği Çerçeve Sözleşmesi, İklim değişikliğine neden olan sera gazı emisyonlarının sınırlandırılmasına yönelik uygulanabilecek stratejilerin ayrıntılı olarak belirlendiği Kyoto Protokolü ve bu konularda yapılan daha bir çok anlaşma tüm kesimleri bağlayıcı niteliktedir. Bu nedenle sanayi işletmeleri de bu yeni dünya düzeninde kendi geleceklerini garanti altın almak için söz konusu ilkeler uymak ve çevre konusunda gerekli hassasiyeti göstermek durumundadırlar. Sosyal sorumluluk sahibi sürdürülebilir üretim ve çevre konusunda hassasiyet taşıyan işletmeler diğerlerin göre her zaman daha önde olacaklardır. (Lyon ve Maxwell, 2008). Çevresel bilincin gelişmesine ve çevresel sorunların çözülmesine dair yapılan önemli toplantı, konferans ve anlaşmalar Şekil 1'de verilmiştir. 


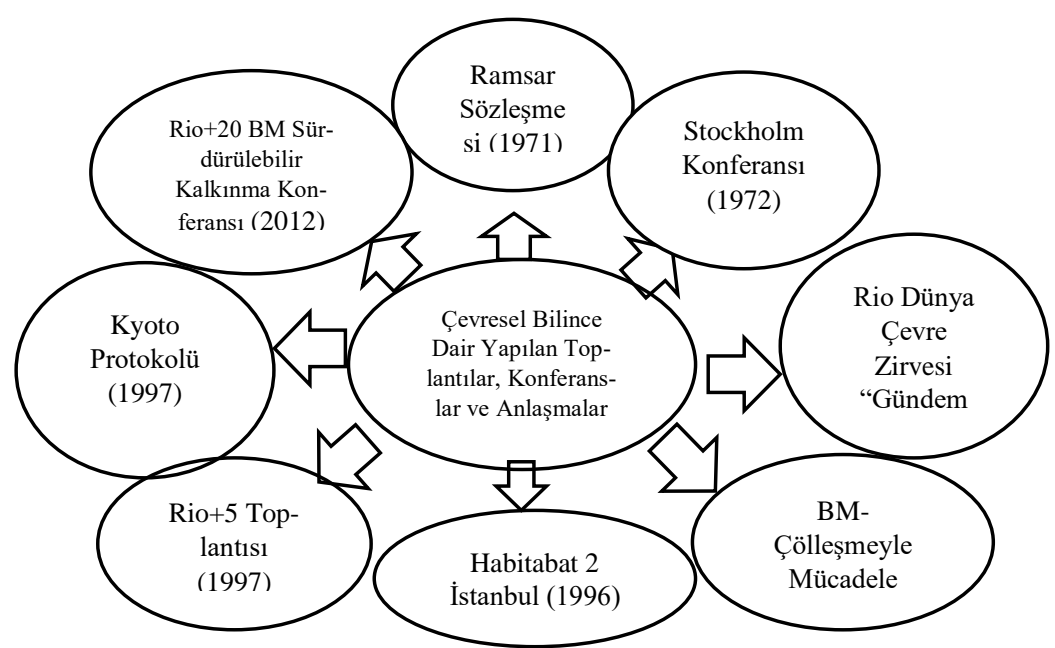

Şekil 1. Çevresel Bilincin Oluşmasına Dair Yapılan Toplantılar, Konferanslar ve Anlaşmalar (Kaynak: Kara, 2019, s.66-67)

Ancak işletmelerce tüm tedbirler alınsa bile ekonomik olarak ülkelerin ve sermayenin sürekli büyüme isteği, doğal çevrenin tahribatını azaltma konusunda bir ikilimde ortaya çıkartmıştır. Her ne kadar işletmeler çevre konusunda dikkatli davransalar bile değişim ve gelişmenin bir gereği olarak diş çevre üzerinde mutlak bir zararı olacaktır. Bu nedenle sanayi işletmelerinin doğal çevre üzerindeki tahribatı tamamen ortadan kaldırmak mümkün olmadığı gibi, sürdrürlebilir üretimin asıl amacı bu zararın en aza indirilmesini sağlamaktır. Özellikle büyük sanayi kuruluşlarının üretimine bağlı olarak ortaya çıkan karbonmonoksitler, kurşun, azot ve benzeri gazların hava üzerindeki olumsuz etkilerini azaltılması için tesislerin bacalarına filtre takılması, atık suların ıslahı için depolama alanları oluşturulması, toprağın kirlenmesini önlemek için ağır metal atıkların yeniden değerlendirilebileceği artıma tesislerinin kurulması, atık ayrıştırmasının özenle yapılması, gürültü sorununun en aza indirilmesi ve doğa içerisinde görüntüyü bozan fiziki yapının dış çevreye uygun olarak tasarlanmasının sanayi işletmelerinin basitçe yerine getirebileceği önlemler olarak sıralayabiliriz (Mont vd., 1999, s.307). 


\section{Yeşil Yönetim}

Yüzyılın başında sanayi devriminin ilk zamanlarından başlayarak artan mekanik üretimin getirdiği doğal çevrenin bozulması ve insan nüfusundaki hızlı artışın ortaya çıkardığı bilinçsiz hareketlerin çevre üzerindeki olumsuz etkileri gün geçtikçe artmaktadır. 1940'lı yıllardan itibaren gelişmiş sanayilerde görülen hava kirliliği, ağır sanayi hamlesi başlatan Japonya gibi ülkelerde ortaya çıkan ciddi öldürücü kimyasal elementler, tarımda kullanılmaya başlanılan ve insan sağlı̆̆ açısından o zamanlar için henüz sonuçları kestirilemeyen ancak günümüzde kanser hastalığına yol açtığı bilinen bir çok ilaç ve 1980'li yıllardan itibaren gelişmeye başlayan ülkelerin plansız sanayileşme hamleleri üzerine tüm dünyada çevrenin korunmasına yönelik düşünce ve eylemler artmaya başlamıştır. İşletmeler açısından ise durum daha farklıdır. Bir taraftan işletmenin var oluş amacı olan kâr hedeflerini karşılamaları gerekirken diğer taraftan da kendilerine hammadde temin eden doğal çevrenin korunmasını sağlamaları gerekmektedir. Bu konudaki bir diğer hususta müşterilerin beklentileri sosyal sorumluluk projeleri kapsamında sürdürülebilir üretim ve sürdürülebilir çevre konularına önemli katkıların yapılmasıdır (Türkmen, 2016).

Kurumsal olarak çevreye saygilı olma durumu ya da diğer bir adıyla yeşil yönetim kavramı 1990'lı yılların başında ortaya çıkmış ve kişilerin/örgütlerin gündemine giren bir konu haline gelmiştir (Lee, 2009, s.1102). Yeşil yönetim kavramı; örgütün sahip olduğu doğal kaynakları en optimal biçimde kullanarak israf etmemesi, tasarruf sağlaması, örgütsel süreçlerin hepsinde çevreyi dikkate alması, çevreyi ve ekolojik dengeyi koruma çabasıdır. Yeşil yönetim düşüncesi salt bir çevreyi koruma çabasından öte bir düşünce biçimi, felsefeyi ifade etmektedir (Kara, 2019, s.4).

Günümüzde gelinen noktada önemli bir çevre bilinci oluşmasının yüklediği sorumluluk nedeniyle işletmelerin organizasyonlarında da değişikliğe gitmelerine, yeşil olarak nitelendirilen yeni bir yönetim felsefesini zorunlu kılmıştır. Bu yeni yönetim tarzı diğer yönetim şeklilerinden farklı olarak işletmenin iç ve dış paydaşları ile tüm süreçlerinin baştan sona kadar planlanmasında çevrenin korunmasını en önemli hedef olarak gören bir anlayışı içermekteydi. Bu şekilde hem işletme hem müşteriler hem de yasal zorunlulukların gerekleri yerine getirilmiş olacaktır. Ayrıca tüm dünyada yeşil yönetim 
uygulayan işletmelere ciddi pozitif bir ayrımcllk yapılması nedeniyle rekabet üstünlüğü sağlaması açısından da bu yönetim tarzı oldukça önemli olmuştur (Usta, 2007). Yeşil yönetimde işletmelerde başarılı olabilmesi için en tepe yönetimin çevre bilinci konusunda ciddi bilgisi bulunmalıdır. Üst yöneticiler, örgütün kendi içerisinde en alt kademeye varıncaya kadar çalışanları sürekli bir şekilde çevre konusunda bilgilendirilmesi, bu konuda uygulamaya konulan üretimsel, yasal ve sosyal süreçlerin koordineli bir biçimde yürütülmesini sağlamalıdırlar (Nemli, 2001). Taylor (1992) tarafından yapılan çalışma neticesinde ortaya konulan "yeşil yönetim çarkı" işletmelerde yeşil yönetim düşüncesinin nasıl işlendiğini ifade etmektedir. Yeşil yönetim çarkı aşağıda Şekil 2' de verilmiştir.

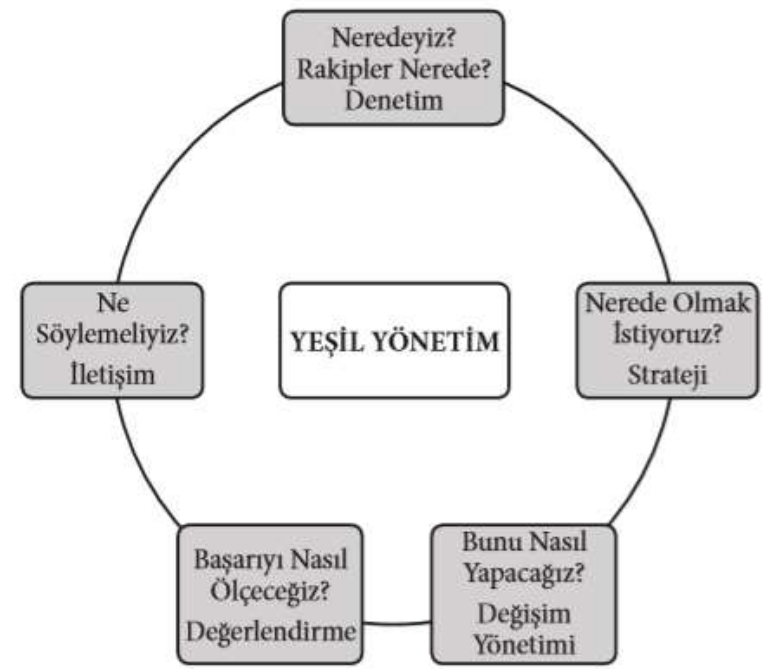

Şekil 2. Yeşil Yönetim Çarkı (Kaynak: Taylor, 1992, s.679; Kara, 2019)

Her yönetim anlayışında olduğu gibi yeşil yönetimin uygulanmasında da bazı unsurlardan bahsedilebilir (Bektaş, 1997):

- Mümkün olduğunca yenilenebilir enerji kaynaklarını kullanmak, bu konuda yeni yol ve yöntemler geliştirmek.

- Çevre konusundaki yeni koruma teknolojileri takip etmek, yatırım yapmak ve uygulamak.

- Üretim atıklarını azaltmak, kendilerine özgü geri dönüşüm süreci geliştirmek. 
- Çevre bilinci konusunda geliştirilen uluslararası hukuksal süreçleri yakından takip etmek ve bunların uygulanması için gerekli tedbirleri almak.

- Uygulanan çevreci yönetim anlayışının başarılı olup olmadığını, kamuoyunun beklentilerini karşılayıp karşılamadığına ilişkin çalışmalar yapmak.

- Çalışan ve müşterilerde Yeşil tüketim bilincinin oluşmasını sağlamak, gerekirse kurum içi ve dışı bu konuda eğitim seminerleri düzenlemek.

- İş yeri çalışma koşullarının yeşil yönetim anlayışına uygun hale getirilmesi.

- Mümkün olduğu takdirde çevre konusundaki projelere sponsor olmak.

- Yeşil yönetimin işletmeye olan maliyetinin muhasebeleştirilmesi ve etki analizinin yapılması.

- Çalışan sendikaları ve sivil toplum örgütleri ile işbirliğine gidilmesi (Callenbach, 1993).

\section{Sanayi İşletmelerinde Çevre Bilinci ve Yeşil Yönetim İlişkisi}

Hızla küreselleşen dünyada faaliyet gösteren tüm örgütler hangi sektör olursa olsun çevreye ve çevre sorunlarına karşı bilinçli olmadan mevcut varlıklarını idame ettirmeleri pek zordur. Bu anlayış çerçevesinde örgütler geleceğe dönük olarak planlayacakları tüm iş kollarında çevre faktörünü de dikkate alarak uzun vadeli plan yapmak ve uygulamak mecburiyetindedirler (Atay ve Dilek, 2013). Dünya çapında birçok işletme, ISO 14001 Çevre Yönetim Standardı ile hem çevre konusunda yasal mevzuatlara ve toplumun isteklerine uymakta, hem de uyguladıkları sürdürülebilir çevre yönetimiyle kaynaklarını etkin bir şekilde kullanarak, rakiplerine karşı sürdürülebilir bir rekabet üstünlügü elde etmeye çalışmaktadır. Konuyla ilgili alan yazın incelendiğinde çevre, çevre bilinci, yeşil yönetim ve örgütlerde yeşil yönetim kavramları örgütler için hayati öneme sahip olduğu ve varlığını devam ettirebilmek için bu olgular üzerinde durması gerektiği fark edilmiştir.

Parlak (2020) tarafından Ordu il ve ilçelerinde organize sanayi bölgesinde faaliyet gösteren 131 işletme üzerinde örgütlerin çevresel tutumları ve çevresel muhasebeye dair tutumlarını saptamak amacıyla bir araştırma yapılmıştır. Araştırma sonuçlarına göre örgüt yöneticilerinin çevresel tutumları ile 
çevre muhasebesine dair sergiledikleri tutum arasında pozitif ve anlamlı bir ilişki olduğu bulunmuştur.

Abbas (2020) tarafından Pakistan'da faaliyet gösteren imalat işletmeleri yöneticileri üzerinde kurumsal sosyal sorumluluğun arac rolü ile toplam kalite yönetiminin yeşil yönetime ve yeşil performansa etkisini belirlemek için bir araştırma yapılmıştır. Araştırma neticesinde uygulanan yapısal eşitlik modeli sonuçları toplam kalite yönetiminin yeşil yönetimi ve yeşil performansı anlamlı ve pozitif etkilediğini, yine toplam kalite yönetiminin kurumsal sosyal sorumluluğu anlamlı ve pozitif olarak etkilediğini ve son olarak ise kurumsal sosyal sorumluluğun toplam kalite yönetimi ve yeşil yönetim/yeşil işletme ilişkisinde kısmi aracılık rolü olduğu saptanmıştır.

Roscoe ve arkadaşları (2019) tarafından yeşil organizasyon kültürü ve firmanın çevresel performansı arasındaki ilişkiyi saptamak için Çinli imalat işletmelerinde çalışan 204 kişi üzerine yapılmıştır. Araştırma sonuçları neticesinde yeşil organizasyon kültürüne sahip işletmelerin çevresel performansını arttırdığını ve çevresel performansa olumlu etki ettiğini saptamışlardır.

Karakuş ve Erdirençelebi (2018) tarafından Konya ilinde faaliyet gösteren KOBİlerin yeşil yönetim düşüncelerinin işletme başarısına, fonksiyonlara ve performansına etkisini ölçmek amacıyla 83 işletme üzerinde yapılan araştırma yapılmıştır. Araştırma sonuçları neticesinde işletmelerin/örgütlerin yeşil yönetim düşüncesi ve yeşil fonksiyonları (yeşil üretim, yeşil muhasebe, yeşil lojistik, yeşil insan kaynakları ve yeşil pazarlama) arasındaki ilişkide işletme başarısını ve performansını anlamlı ve yüksek düzeyle etkilediği ortaya konulmuştur.

Gonenc ve Scholtens (2017) tarafindan fosil yakıt firmaları üzerinde çalışma yapılmıştır. Çalışmada 2002- 2013 döneminden faaliyet gösteren 2736 işletmenin çevresel sorumluluğunun, çevresel performanslarının ve işletmede uyguladıkları yeşil düşüncesinin işletmenin finansal verimliliğini ne derecede değiştirip değiştirmediği tespit edilmeye çalışılmıştır. Yapılan çalişma sonuçlara göre, işletmenin çevresel sorumluluğu, çevresel performansının ve yeşil düşüncesinin işletmelerin hisse ve özkaynak karlılığına etki etmediğini, kömür işletmelerinin karlılığını düşürdüğünü ayrıca, petrol ve gaz işletmelerinin karlılıklarını olumlu olarak etkilediği sonucuna ulaşılmıştır.

Ceyhan ve Ada (2015) tarafından Kahramanmaraş ilinde 121 üretim işletmesi (tekstil, gıda ve metal mutfak eşya sanayi) üzerinde gerçekleştirilen, işletmelerin/örgütlerin çevre duyarlılığını saptamak ve çevresel duyarlılığının 
işletmelere/örgütlere oturmasını sağlamak için yapılması gerekenleri belirlemek için yapılan çalışmada ise; ilde varlığını devam ettiren büyük işletmelerin küçük işletmelere göre çevresel duyarlılığının daha fazla olduğu, genel olarak ise ildeki tüm işletmelerde artık çevresel sorunların fark edildiği ve bu konuda bir bilinç sağlandığı ortaya konulmuştur.

Jayaram ve Avittathur (2014) tarafından yeşil tedarik zinciri yönetiminin Hindistan ekonomisine sağlayacağı katkıları ölçmek amacıyla 65 işletme (çelik, ilaç elektrik-elektronik, otomobil ve yatırım sektörleri) üzerinde çalışma yapılmıştır. Çalışma sonuçlarına göre müşteri baskısı ve çevresel stratejiler yeşil tedarik zincirini etkileyen önemli faktörler olduğu tespit edilmiştir.

Teixeira ve arkadaşları (2013) tarafından yapılan çalışmada ise yeşil yönetim düşüncesinin örgüte uygulanması, örgüte birçok yeni ve stratejik firsat sunacağı belirtilmiştir.

Ones ve Dilchert (2012) tarafından yapılan çalışmaya göre ise, örgüt çalışanının yeşil iş gören davranışı göstermesi işletmenin yeşile ve çevresel sürdürülebilirliğine katkı verdikleri sonucuna ulaşmışlardır.

Moneva ve Ortas (2009) tarafından Avrupa!da faaliyette bulunan 230 işletme yöneticisi üzerinde çevresel hassasiyetlerinin işletmenin karlılığına ne kadar etki ettiğini saptamak için çalışma yapılmıştır. Çalışma neticesinde çevresel hassasiyetleri yüksek olan yöneticilerin bulunduğu işletmelerin karlılığının ve finansal performansının daha yüksek olduğunu saptamıştır.

Yine Claver vd. (2007) ve Molina-Azorin vd. (2009) tarafindan yapılan çalışmaya göre yeşil yönetim ve çevresel uygulamaların işletme performansına pozitif yönde etkilediği tespik edilmiştir.

Chavan (2005) tarafından yapılan çevresel yönetim uygulamalarının küçük ve orta ölçekli işletmelere uygulanmasına dair yapılan araştırmada ise çevresel bilinç, çevresel uygulamaların kurum içerisinde işletme içi ve işletme dışı çevresel analiz yapılması gerekliliği ortaya konulmuştur.

Karabulut (2003), tarafından yapılan çalışmada ise işletme performansı etkileyen önemli unsurlardan birisinin de çevreye saygı ve çevre bilincinin olduğu saptanmış ve örgütlerde çevresel düşüncenin işletme performansına olumlu yönde katkı sağladığı belirtilmiştir. Yapılan araştırma sonucunda, işletme fonksiyonları itibari ile yeşil yönetim anlayışına uygun faaliyetlerin uygulanma düzeyleri arttıkça işletme başarı göstergelerindeki değişim düzeyinin de artacağı sonucuna ulaşılmıştır. 
Florida ve Davison (2001) tarafından yapılan çalışmada ise yine örgüte yeşil yönetim düşüncesinin ve uygulamalarının hakim olması işletmeye yeni fırsatlar sağlayacağı belirtilmiştir.

Handfield ve arkadaşları (1997) tarafından yapılan çalışmada, işletme başarılı olmak istiyorsa çevresel düşüncenin, yeşil yönetim düşüncesinin işletmeye uygulanması gerektiğini savunmuşlardır.

Porter ve Van Der Linde (1995) tarafından yapılan çalışmada örgütte yeşil düşüncenin ve çevre bilincinin olması işletmeye rakiplerine göre büyük bir avantaj sağladığını saptamıştır.

\section{Sanayi İşletmelerinde Çevre Bilinci ve Yeşil Yönetim Örnekleri}

Günümüzde yeşil yönetim düşüncesine ve çevre bilincine sahip işletmeler, çevrenin ve yeşil uygulamaların geleceğin rekabetçi silahı olduğunun farkına varmış ve buna dönük uygulamalar yapılmaya başlanmıştır. Bugün piyasa faaliyet gösteren birçok başarılı işletme çevresel bilince sahip ve çevresel duyarlılığa sahip işletmelerin varlığı dikkat çekmektedir.

"Yeşil yönetim konusunda önde gelen şirketlerden birisi olan Toyota, bünyesinde ürettiği Hybrid araçlar sayesinde piyasada rekabet avantajı kazanmıştır. Interbrand tarafından yapılan araştırmaya göre Toyota'nın bu hamlesi marka değerini \%47 oranında arttırmıştır. Fujitsu'nun üstün teknolojisi ve Siemens'in şirketinin güçlü endüstrisi ile ortaya çkan Fijutsu Siemens, 3 tane kurduğu "dönüşüm merkezi" ile birlikte ortaya çıkan atıkların en uygun şekilde ayrıştııılmasını sağlamaktadır. Şirketin çalışanları tarafından sadece çalıştıkları ortam için değil, evlerinde de ortaya çıkan pil, kağıt vb. atıklar şirkete getirilmekte ve ayrıştıılması gerçekleştirilmektedir. Şirket tarafından uygulanan bu çevreci davranış sadece şirket içerisiyle sınırlı kalmamış ve 'yeşil çalışan' ortaya çıkarmıştır" (https://www.capital.com.tr).

"Tetra Pak şirketi sıfır atık uygulamalarına ve geri dönüşümlü ambalaj üretimiyle birlikte yeşil örgüt yapısına bürünmüştür. Üretiminin \%75 doğal kaynağa bağl1 olan işletme, örgütte yeşil yönetim düşüncesinin benimsenmesiyle doğal kaynak kullanımını en aza indirmiş ve üretim bölümünde çeşitli proseslerin kullanılmasıyla birlikte doğal kaynak kullanımını büyük oranda azaltmıştır. İşletmede uygulanan yeşil süreçler enerji alanında \%5 tasarruf ettirirken, su kaynaklarının kullanımında ise \%15 azalma görülmüştür" 
(https://www.capital.com.tr). Dünyanın farklı bölgelerinde uygulanan yeşil yönetim düşüncesinin uygulama örnekleri Tablo 1' de verilmiştir (Aydın, 2017).

Tablo 1. Yeşil Yönetim Uygulama Örnekleri

\begin{tabular}{|c|c|c|c|}
\hline Firma Adı & Üretim Alanı & $\begin{array}{l}\text { Nerede Faaliyet } \\
\text { Gösteriyor }\end{array}$ & Yeşil Üretim Uygulaması \\
\hline BMW & Otomobil Üretimi & Almanya & $\mathrm{Su}, \mathrm{CO} 2$ Karbon yayılımı \\
\hline $\begin{array}{l}\text { Asaş Alüminyum } \\
\text { Sanayi ve Ticaret A.Ş. }\end{array}$ & $\begin{array}{l}\text { Alüminyum Profil } \\
\text { Sistemleri }\end{array}$ & Sakarya/Türkiye & Tüketilen Enerjiden \%90 Tasarruf \\
\hline $\begin{array}{l}\text { Ford Otosan } \\
\text { Otomotiv } \\
\text { Sanayi Anonim } \\
\text { Şirketi Gölcük }\end{array}$ & Otomobil Üretimi & Gölcük/Türkiye & $\begin{array}{l}\text { Çok Katmanlı Üretim ile Hurda } \\
\text { ve Boya Maddesi Tasarrufu }\end{array}$ \\
\hline Arçelik A.Ş. & Elektronik Eşya & Türkiye & $\begin{array}{l}\text { Doğal Kaynakları Az } \\
\text { Tüketen Yüksek Verimlilik } \\
\text { (Eko-Verimlilik) }\end{array}$ \\
\hline Apple & Bilgisayar & Dünya & Enerji Tasarrufu \\
\hline Temsa & Hibrit Otomobil & Türkiye & CO2 Karbon yayılımı \\
\hline $\begin{array}{l}\text { Nuh Çimento } \\
\text { Sanayi A.Ş. }\end{array}$ & Çimento & İzmit/Türkiye & Sera Gazı Azaltımı \\
\hline
\end{tabular}

Kaynak: Aydın, 2017

\section{Sonuç ve Değerlendirme}

Günümüzde artık küresel bir problem olan çevresel sorunların çözümü konusunda gelişmiş ülkelerin öncülüğünde ve sivil toplum örgütlerinin iş birliğinde uluslararası bağlayıcılığı bulunan birçok proje geliştirilmekte ve hayata geçirilmektedir. Söz konusu projelerin çoğunluğu sonuç olarak insanların genelini ilgilendirmekle birlikte asıl uygulama kısmının yürütücülüğü üretim yapan işletmeleri yani sanayi işletmelerini direk olarak ilgilendirmektedir. Üretim süreçlerinin doğal olarak çevre üzerinde olumsuz bir etkisi bulunmaktadır ve bunun tamamen ortadan kaldırılması da imkansızdır. Bu nedenle çevre konusundaki tüm çalışmalar tahribatı en aza indirecek yeni yol ve yöntemlerin bulunması üzerinedir. Özellikle son çeyrek yüzyılda çevre konusundaki alınan kararların tamamına yakını atıkların azaltılması, ıslah edilmesi, gaz salınımının kontrol altına alınması, geri dönüşüm konusunun zorunlu hale getirilmesi oluşturmuştur.

Bu zorunluluk önlemlerin tamamının işletmelerin, özellikle de büyük ölçekte üretim yapan uluslararası sanayi işletmeleri tarafından uygulamasını 
nasıl ve ne şekilde olacağı sorununu ortaya çıartmış ve çözüm olarak da işletmecilikte yeni bir kavram olarak yeşil yönetim felsefesi hayata geçirilmiştir. İşletmenin tüm süreçlerinin çevreye duyarlı olacak şekilde tasarlanmasını öngören bu yönetim şekli, gün geçtikçe de daha profesyonel bir hal alarak gelişmektedir. Bu çalışmada yeşil yönetim konusunda literatürdeki çalışmalar ile uluslararası projelerin incelenmiş ve sanayi işletmelerinde, söz konusu yönetim tarzının yasal ve üretimsel süreçler, paydaşlarla olan ilişkiler ile son atıklar konusunda işletmenin fayda ve zararları üzerinde değerlendirmelerde bulunulmuştur.

Çevrenin korunması için işletmelerce uyulması gereken ilk zorunluluğun yasal süreçler olduğu söylenebilir. 1987 yılında Birleşmiş Milletler genel kurulunda ortaya çıkan sürdürülebilir kalkınma kavramı, bu yasal süreçlerin de altyapısını oluşturmuştur. Ağır sanayi üretimi yapan işletmelerin bacalarına filtre takılması, atıkların ayrıştırılacağı geri dönüşüm alanlarının bulunması, sıvı atık bulunan tesislerde arıtma sistemi kurulması ve zehirli gazlar ile radyasyon gibi radyoaktif atıkların kontrol altında tutulması için gerekli tedbirlerin (uzman personel istihdamı, gaz ölçüm sistemi kurulması v.b.) alınmasının, tüm dünyada çevre koruma konusunda işletmeleri maddi ve manevi olarak zorlayan en önemli süreç olduğu söylenebilir. İşletme bütçesine ciddi bir yük getiren bu hukuksal zorunlulukların gelişmiş ülkelerde daha sıkı takibi yapılırken az gelişmiş ve gelişmekte olan ülkelerde bu süreçlerin aksak olarak yürütüldüğü görülmektedir. Diğer taraftan birçok devlet ve çevreci sivil toplum örgütü tarafından sanayi işletmeleri için finansal destekler sağlanmaktadır.

Sanayi işletmeleri için çevre bilinci ve yeşil yönetim konusunda önemli bir konu olan ikinci süreç üretiminde çevreci bir yaklaşımın nasıl sağlanacağı hususudur. Özellikle hammadenin temini esnasında doğal kaynakların tahribatı düşünüldügünnde ortaya çıan çevre yıkımı için önemli tedbirlerin alınması zorunlu bir hale gelmiştir. Ayrıca mamulün üretiminden dağıtımına kadar olan süreçte de bir dizi tedbirlerin alınması gerekmektedir. Bu nedenle günümüzde gelişen teknolojiler sayesinde en ucuz ve etkili hammade konusunda alternatif kaynakların bulunması için işletmeler Ar-Ge çalışmalarına ciddi kaynak ayırmaktadırlar. Üretim sürecinde geri dönüşüme kazandırılabilir malzemeler tercih edilirken, atmosfer dengesini bozacak gazların kullanımının sınırlandırılması, ürün ambalajlarının çevreye duyarlı hale getirilmesi, lojistik ve dağıtım konularında çevre dostu vasıtaların kullanılması ile 
personelin çevreci anlayışa sahip bireyler olarak eğitilmesi konularında önemli adımlar atılmaktadır.

Sanayi işletmelerini çevre konusunda ilgilendiren diğer önemli bir konu da müşterilerdeki çevre bilinci ve satış sonrası atıkların değerlendirilmesiyle ilgilidir. Aslında bir işletmenin ne şekilde ve nasıl üretim yapacağını belirleyen temel etkenlerden birisi de müşterilerin istek ve beklentileridir. Yani müşterilerin çevre konusunda bilinçli olması işletmeleri de bu konuda duyarlı davranmaya zorlamaktadır. Öte taraftan ise işletmenin bütün faaliyetlerinde yeşil yönetim uygulaması müşteriler üzerinde çevrenin korunmasına yönelik farkındalık ortaya çıkartmaktadır. Bu şekilde hem işletme hem de müşteriler çevrenin korunmasına yönelik birbirlerini tamamlayan unsurlar olarak görülebilir. Sanayi işletmelerinin çevreye duyarlılık konusunda diğer önemli bir görevi de sosyal sorumluluk projeleri geliştirmek ve uygulamaktır. Sokak hayvanları için barınaklar yapılması, doğanın ağaçlandırılması, naylon ve kağıt atıkların toplanmasında maddi teşvik sağlanması, denizlerin temizlenmesinde öncü hareketler gibi birçok projeler ile işletmeler çevrenin korunmasına katkı sunmaktadırlar. 
EXTENDED ABSTRACT

\title{
Environment Consciousness in the Industrial Businesses and an Evaluation on Green Management
}

\author{
Ergün Kara - Attila Kaya \\ Osmaniye Korkut Ata University
}

The relationship between environment and human constitutes a complex and wearing whole that will last forever as a necessity of life. For this reason, it is unthinkable for human beings to be independent from the environment. However, in this relationship, because people do not act attentively to protect the environment, the point reached today has reached the point of disaster regarding the destruction of the natural environment. While the invention of the machine, which was a great turning point for humanity in a relatively recent history, quickly facilitated things in every field, nobody thought that it would destroy our natural environment in a short time. Parallel to the increase in production, factories at global scale with developed many sectors were established, and the production capacity was further increased with technologically developed machinery and equipment. However, this intensive production has brought problems such as the rapid consumption of natural resources, air, water, soil and noise pollution and the deterioration of the ecological balance (Haden at el., 2009).

They are in a close relationship as production is structurally dependent on natural resources. As the expectations and desires of people change in our age, there are problems in obtaining the resources required for diversified production activities. Since the indiscriminate and unplanned spending of the already scarce natural resources will cause a disaster in the future, businesses now take measures to protect the ecological balance as well as productivity and profitability. Industrial enterprises are the most important actors of the concept of "environmentally friendly business administration" created in line with this idea. Since industrial enterprises, which are the main elements of production, can cause irreparable damages on the basic elements of nature, these enterprises should take the most important 
measures for the protection of the environment. For a healthy and successful environmental management, business bodies should act as a whole in accordance with the mission objectives, and act in a structure that takes into account the wishes and expectations of all factors that shape the activities (stakeholders, customers, partners, legal obligations).

The state of being respectful to the environment, or in other words, the concept of green management emerged in the early 1990s and has become an issue on the agenda of individuals / organizations (Lee, 2009: 1102). Green management concept; It is an effort to protect the environment and ecological balance by using the natural resources of the organization in the most optimal way, not to waste, saving, taking into account the environment in all organizational processes. The idea of green management is more than just an effort to protect the environment, it expresses a way of thinking and philosophy (Kara, 2019: 4).

As in every management understanding, some elements can be mentioned in the implementation of green management (Bektaş, 1997):

- To use renewable energy sources as much as possible, to develop new ways and methods in this regard.

- To follow, invest and apply new environmental protection technologies.

- To reduce production wastes, to develop a unique recycling process.

- To closely follow international legal processes developed on environmental awareness and to take necessary measures for their implementation.

- To carry out studies on whether the applied environmental management approach is successful and whether it meets the expectations of the public.

- To raise awareness of green consumption among employees and customers, if necessary, to organize training seminars on this issue within and outside the institution.

- Making workplace working conditions compatible with the green management approach.

- To sponsor environmental projects whenever possible.

- Accounting for the cost of green management to the enterprise and conducting impact analysis. 
- Cooperating with employee unions and non-governmental organizations (Callenbach, 1993)

Today, many internationally binding projects are developed and implemented under the leadership of developed countries and in cooperation with non-governmental organizations in the solution of environmental problems, which are now a global problem. Although most of the projects in question concern the general public as a result, the main application part directly concerns the manufacturing enterprises, namely the industrial enterprises. Production processes naturally have a negative impact on the environment, and it is impossible to eliminate this completely. For this reason, all studies on the environment are based on finding new ways and methods to minimize destruction. Especially in the last quarter century, almost all of the decisions taken on the environment have been the reduction of waste, rehabilitation, control of gas emissions, and the necessity of recycling.

This necessity has revealed the problem of how and how all of the measures will be implemented by enterprises, especially international industrial enterprises producing large scale production, and as a solution, green management philosophy has been implemented as a new concept in business administration. This management style, which foresees the design of all processes of the business to be environmentally sensitive, is developing day by day by becoming more professional. In this study, the studies in the literature on green management and international projects were examined and the legal and productive processes of the management style in question, the relations with stakeholders and the benefits and harms of the enterprise were evaluated on the last waste.

The second important process for environmental awareness and green management for industrial enterprises is how to ensure an environmentally friendly approach in production. Considering the destruction of natural resources, especially during the supply of raw materials, it has become necessary to take important measures for the environmental destruction that occurs. In addition, a series of measures must be taken in the process from the production of the product to distribution. For this reason, enterprises allocate serious resources to $R \& D$ studies in order to find alternative resources for the cheapest and most effective raw materials thanks to today's devel- 
oping technologies. While recyclable materials are preferred in the production process, important steps are taken to limit the use of gases that will disrupt the atmosphere balance, to make product packaging environmentally sensitive, to use environmentally friendly means in logistics and distribution, and to train personnel as individuals with an environmentalist understanding.

\section{Kaynakça / References}

Abbas, J. (2020). Impact of total quality management on corporate green performance through the mediating role of corporate social responsibility. Journal of Cleaner Production, 242, 2-12. https://doi.org/10.1016/j.jclepro.2019.118458.

Akdoğan, A. (2003). Çevreye duyarl yönetim ve işletmecilik.. Kayseri: Ticaret Odası Yayınları.

Atay, L. ve Dilek, E. (2013). Konaklama işletmelerinde yeşil pazarlama uygulamaları: Ibıs Otel Örneği, Süleyman Demirel Üniversitesi, İ.̇.B.F Dergisi, 18(1),203-219.

Aydın, N. (2017). Yeşil üretim uygulamaları. International Conference On Eurasian Economies. 356-360, (Bildiriler).

Bektaş, H. (1997). ISO 14000'e genel bir bakış. 2. Ulusal Çevre Mühendisliği Kongresi, 45 Aralık, İstanbul.

Bolat, B. ve Sıtkı, G. (2003). ISO 14000 Çevre Yönetim Sistemi Uygulamasında Etken Olan Faktörler, İTÜ Dergisi, 2(2), 39-48.

Callenbach, E. (1993). Ecomanagement: the elmwood guide to ecological auditing and sustainable business. Berrett-Koehler Publishers, San Francisco, 85-86.

Capital. (t.y). Anasayfa. 11.08.2020 tarihinde https://www.capital.com.tr adresinden erişilmiştir.

Ceyhan, S. ve Ada, S. (2015). İşletme fonksiyonları açısından çevreye duyarlı işletmecilik. Uluslararası Yönetim İktisat ve İşletme Dergisi, 11(26), 115-137.

Chavan, M. (2005). An appraisal of environment management systems: A Competitive advantage for small businesses, Management Environmental Quality: An International Journal, 16(5), 444-463.

Chen, Y. S. (2008). The Driver of green innovation and green image - green core competence, Journal of Business Ethics, 81, 531-543.

Claver, E., Lopez, M. D., Molina, J. F., ve Tarí, J. J. (2007). Environmental management and firm performance: A Case study. Journal of Environmental Management, 84(4), 606-619. https://doi.org/10.1016.

Endüstri Devriminin Çevresel Etkileri (2020). Ekolojist. 28.07.2020 trihinde http://ekolojist.net/endustri-devriminin-cevresel-etkileri adresinden erişilmiştir. 
Florida, R., ve Davison, D. (2001). Gaining from green management: Environmental management systems inside and outside the factory. California Management Review, 43(3), 64-84.

Gonenc, H. ve Scholtens, B. (2017). Environmental and financial performance of fossil fuel firms: A closer inspection of their interaction. Ecol. Econ. 132, 307-328. (9) (PDF) Responsibility and Performance Relationship in the Banking Industry. Available from: https://www.researchgate.net/publication/333823248 Responsibility and Performance Relationship in the Banking Industry.

Greeno, J. L., Robinson, S. N. (1992). Rethinking Corporate Environmental Management. The Columbia Journal of World Business.

Haden, S. S. P., Oyler, J. D., ve Humphreys, J. H. (2009). Historical, practical, and theoretical perspectives on green management: An exploratory analysis. Management Decision, 47(7), 1041-1055. https://doi.org/10.1108/00251740910978287.

Handfield, R. B., Walton, S. V., Seegers, L. K., ve Melnyk, S. A. (1997). 'Green'Value Chain practices in the furniture industry. Journal of Operations Management, 15(4), 293-315. https://doi.org/10.1016/S0272-6963(97)00004-1.

Jayaram, J. ve Avittathur, B. (2015). Green supply chains: A perspective from an emerging economy. Int. J. Production Economics, 164, 234-244.

Kara, E. (2019). Yeşil yönetim ve çevre bilinci: Konaklama işletmeleri için bir modelleme. Akademisyen Kitabevi: Ankara.

Karabulut, E. (2003). İşletmelerde çevre bilinci ve yeşil yönetim uygulamalarının işletme başarısına katkısını incelemeye yönelik bir araştırma. Yayımlanmış Doktora tezi, İstanbul Üniversitesi, İstanbul.

Karakuş, G., Erdirençelebi, G. (2018). İşletmelerin yeşil yönetim algılarının işletme performansı üzerindeki etkisini ölçmeye yönelik bir araştırma. Işletme Araştırmaları Dergisi, 10 (4), 681-704.

Krajnc, D. ve Glavič, P. (2003). Indicators of sustainable production. Clean technologies and environmental policy, 5 (3-4), 279-288.

Lee, K. H. (2009). Why and how to adopt green management into business organizations? The case study of Korean SMEs in manufacturing industry. Management Decision, 47(7), 1101-1121. https://doi.org/10.1108/00251740910978322.

Lee, S. Y. ve S. K. Rhee (2007). The Change in corporate environmental strategies: A longitudinal empirical study", Management Decision, 45(2).

Lo, Chris K.Y., Yeung, Andy C.L. ve Cheng, T.C.E. (2012). The impact of environmental management systems on financial performance in fashion and textiles industries. Int. J. Production Economics, 135, 561-567 
Lyon, T.P. ve Maxwell, J.W. (2008) On the profitability of corporate environmentalism. Thomas et al.(eds.) Oxford Handbook of Managerial Economics, Oxford University Press.

Manaktola, K. and Jauhari, V. (2007). Exploring consumer attitude and behaviour towards green practices in the lodging industry in India. International Journal of Contemporary Hospitality Management, 19(5), 364-377.

Martinuzzi, A., Elisabeth, H. ve Bernhard, O. (2000). "Ecoprofit”. Greener Management International, 30, 83-97.

Molina-Azorin, J. F., Claver-Cortes, E., Lopez-Gamero, M. D. ve Tari, J. J. (2009). Green management and financial performance: $\underline{A}$ literature review. Management Decision, 47(7), 1080-1100. https://doi.org/10.1108/00251740910978313.

Moneva, J. M. ve Ortas, E. (2009). Corporate environmental and financial performance: A multivariate approach, Emerald Industrial ManagementEData Systems, 110(2).

Mont, O., Plepys, A. ve Durkin, M. (1999). Transferring cleaner production to Eastern Europe: Experiences from cleaner production training programme in Roslavl, Russia,1998., Journal of Cleaner Production, S. 7, s. 307-311.

Morrow, D. ve Rondinelli, D. (2002). Adopting corporate environmental management Systms: Motivations and results of ISO 14001 and EMAS Certification, European Journal, 2 (20), 159-171.

Nemli, E. (2001). Çevreye duyarlı yönetim anlayışı: İstanbul Üniversitesi. Siyasal Bilgiler Fakültesi Dergisi, 23-24, 211-234.

Ones, D. S., ve Dilchert, S. (2012). Environmental sustainability at work: A call to action. Industrial and Organizational Psychology, 5(4), 444-466. https://doi.org/10.1111/j.1754-9434.2012.01478.x.

Parlak, N. (2020). İşletmelerin çevresel yaklaşımları ve çevre muhasebesine verdikleri önem: Ordu il ve ilçelerindeki organize sanayi bölgeleri üzerine bir araştırma. Muhasebe ve Finansman Dergisi, 86, 167-182. DOI: 10.25095/mufad.710255.

Porter, M. E., ve Van Der Linde, C. (1995). Green and competitive: Ending the stalemate. Harvard Business Review, 120-134.

Roscoe, S., Subramanian, N., Jabbour CJC ve Chong T. (2019). Green human resource management and the enablers of green organisational culture: Enhancing a firm's environmental performance for sustainable development, Bus Strat Env.1-13. https://doi.org/10.1002/bse.2277. 
Sharma, S. H. ve Vredenburg, H. (1998), Proactive corporate environmental strategy and the development of competitively valuable organizational capabilities, Strategic Management Journal, 19.

Taylor, R. S. (1992). Green Management: The Next Competttive Weapon. Futures, 669-680.

Teixeira, A. A., Bello, V. F., ve de Oliveira, J. H. C. (2013). Article information: Greening a Brazilian Cotton Seed Processing Company From Challenges to Strategic Opportunities. World Journal of Science, Technology and Sustainable Development, 10(2), 123-130. https://doi.org/http://dx.doi.org/10.1108/20425941311323127.

Türkmen M. A. (2016). Üretime çevre odaklı bir bakış. An Envıronmental- International Journal Of Social Science, 46, 155-171

Usta, R. (2007). Otel işletmeciliğinde çeore yönetim sistemi uygulamaları. Yayınlanmamış Yüksek Lisans Tezi, Selçuk Üniversitesi Sosyal Bilimler Enstitüsü, Konya.

Yacooub, A. ve Fresner, J. (2006). Half is enough - An introduction to cleaner production. Beirut, Lebanon: LCPC Press.

\section{Kaynakça Bilgisi / Citation Information}

Kara, E. ve Kaya, A. (2020). Sanayi işletmelerinde çevre bilinci ve yeşil yönetim üzerine bir değerlendirme. OPUS-Uluslararası Toplum Araştırmaları Dergisi, 16(30), 3161-3182. DOI: 10.26466/opus.779229 